\title{
PSYCHOSOCIAL RISK FACTORS FOR LOW BACK PAIN AND ABSENTEEISM AMONG SLOVENIAN PROFESSIONAL DRIVERS
}

\author{
Friderika Kresal ${ }^{1}$, Jana Suklan², Vasja Roblek ${ }^{3}$, Andrej Jerman ${ }^{4}$, Maja Meško ${ }^{3}$ \\ ${ }^{1}$ Fizioterapevtika, Institution of higher education, Medvode, Slovenia

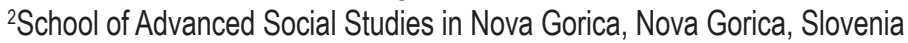 \\ ${ }^{3}$ Faculty of management, University of Primorska, Koper, Slovenia \\ ${ }^{4}$ Ljubljanski potniški promet, d.d., Ljubljana, Slovenia
}

\begin{abstract}
SUMMARY
Objective: The aim of this study was to determine the most common psychosocial risk factors for absenteeism and the extent to which low back pain occurs among Slovenian professional drivers as result of various psychosocial risk factors.

Method: The study involved 275 professional drivers, mostly men (mean age 41.6 years). Statistical data analysis was conducted using SPSS package version 21, MS Excel version 2007 and Pajek, version 3. The main method for data processing was regression analysis.

Results: The results of the quantitative survey showed that lower back pain is mostly caused by lifting and carrying heavy loads, inadequate working conditions, poor physical fitness, regular nights out, shift work, and stress. Dissatisfaction with work, shift work and unsuitable working conditions significantly affect the incidence of low back pain. Absenteeism is influenced by factors such as dissatisfaction at work, disrespectful attitude of managers, unsuitable working conditions, personal dissatisfaction, lack of understanding of the partner, and enjoying nightlife on a regular basis.

Conclusions: The study clarifies the unexplained holistic psychosocial risk factors and treatment effects on health in the population of professional drivers. Such factors can lead to absenteeism. The study also provides initial demonstration research in the Slovenian practice. Furthermore, it provides solutions in a holistic approach to solve the problem of risk factors management.
\end{abstract}

Key words: absenteeism, low back pain, professional drivers, psychosocial factors, regression analysis

Address for correspondence: M. Meško, Faculty of Management, University of Primorska, Cankarjeva ulica 5, 6101 Koper, Slovenia. E-mail: maja.mesko@fm-kp.si

https://doi.org/10.21101/cejph.a4385

\section{INTRODUCTION}

Current findings indicate that 60 to 90 percent of the world's population is confronted with low back pain at least once in their life. People are commonly confronted with low back pain at the prime of life between 20 and 50 years of age, at peak of mental and physical abilities and during the most active period of life. Low back pain is widely acknowledged as an important health and socioeconomic problem which plagues a large segment of the population in industrialized countries. Frequent attacks of back pain are the reason for short- or long-term absences from work and premature disability retirement, causing a large economic burden for both patients and society as a whole (1-5).

Waddell (6) classified low back pain as a medical and health disaster of the last century. The reason for this is attributed primarily to dealing with back pain, according to the medical model which is followed by the entire health care of western countries. This model is mainly based on the recognition of signs and symptoms, forming a diagnosis, treating a patient with physical therapy, and anticipating a positive treatment outcome. But the model ignores the human biological, psychological and social determinants. Mainly due to the interdependence of various symptoms, biological and psychological effects and finally social risk factors that determine an individual's health and the effects of disease, an individual with low back pain must be looked at holistically. The biopsychosocial treatment model offers this vantage point.

Causes of low back pain should not always be perceived as only functional and organic disorders, as they also relate to the personality structure of the individual, his/her views, attitudes, and lifestyle (6). Low back pain is often associated with stress, which is a response of the organism to a real or imaginary danger, characterized by increasing awareness of bodily sensations, severity of pain and a lower pain threshold. In a stressful situation, a person is much more concerned about his/her health, experiences more pain and is more sensitive. A person experiences stress when threatening events exceed coping and defence capabilities. The perception of and dealing with a particular situation is reflected in the physical and emotional responses (7-10). For these reasons we can expect better rehabilitation outcome when we considered the patient as a whole and take into account the fact that when experiencing pain, physical problems cannot be separated from mental ones. Patients definitely need physical treatment for their physical problems, but more important is the help and support when coping with pain and the commencement of normal activity and behaviour (6). 
After reviewing the existing literature on the topic of psychosocial risk factors in different professions, we note that professional drivers are a high-risk group for low back pain. The causes of their pain-state can be understood as the result of their specific lifestyle $(7,8)$. Our objective was to determine the most common psychosocial risk factors for absenteeism and the extent to which back pain occurs among Slovenian professional drivers as result of different psychosocial risk factors.

\section{MATERIALS AND METHODS}

\section{Sample of Professional Drivers}

Empirical research was limited to employees in the geographical area of the Republic of Slovenia. Fieldwork was conducted from October to December 2013. With the help of the Chamber of Commerce of Slovenia and the Association of Drivers and Mechanics of Slovenia, our study sample was based on the lists of employed professional drivers. We sent a cover letter and invitation to participate in the study to 350 randomly selected companies. Our sample includes 275 professional drivers. The survey was anonymous and drivers decided to participate voluntarily. The purpose of the survey was presented to them beforehand.

Respondents ( $93.8 \%$ of men and $6.2 \%$ of women) were aged from 23 to 66 years (mean $41.6 \pm 8.9$ years). Professional drivers worked in their profession from 1 to 34 years (mean 13.5 years \pm 8.3 years). According to body mass index, it turns out that most professional drivers are moderately obese $(62.5 \%)$, a quarter of them have a normal body weight, while a tenth of them are severely obese or very severely obese.

Most professional drivers were driving personal vehicles, specifically taxies (26.2\%), a quarter drove buses (25.5\%), 16.0\% drove a lorry internationally. In the last year they had been absent from work from 0 to 90 days, on average, 16.6 days, of which a mean absence of 5.5 days was due to the occurrence of low back pain. On average, absence due to low back pain accounted for $22.2 \%$ of all absences.

\section{Measurement Instrument}

The first part of the questionnaire consisted of questions to determine socio-demographic data. In the second part we examined the psychosocial risk factors as a cause for absenteeism among Slovenian professional drivers. For the factors relating to psychosocial risk factors of low back pain, we used 7-step Likert scale. Respondents were asked to define and select factors by circling the numbers from 1 to 7 , circling the one that indicated a certain degree of agreement with the statement; 1 meant no effect on low back pain and 7 a great influence on low back pain. The questionnaire also included questions related to absenteeism.

\section{Hypothesis}

The key causes of low back pain include external factors (lifting heavy loads, inadequate working conditions, poor physical condition, and others), as well as subjective factors (personal discontent, dissatisfaction with work, disrespectful attitude of management towards employees, misunderstanding with partner, poor relations between colleagues, and others). Research increasingly indicates that for the occurrence of low back pain, stress is very important, which is in close connection to other, particularly negative psychosocial factors.

Through our research, we wanted to determine to what extent psychosocial factors are present and contribute to the occurrence of low back pain and absenteeism. We investigated the relationship between psychosocial factors and the presence of low back pain and absenteeism. Two hypotheses were tested:

The presence of psychosocial factors increases the presence of low back pain among professional drivers; and

The presence of low back pain increases inability to work (absenteeism).

\section{Methods of Data Processing}

The data obtained were processed with statistical software program IBM SPSS Statistics Desktop 22.0. Descriptive statistics were calculated and hypotheses were tested. Statistical significance was considered at level equal or smaller to 0.05 .

Segmentation of the sample was made by using a hierarchical grouping of Ward's procedure combining units. Based on the dendrogram, we decided for the optimal number of heterogeneous groups for comparison.

For the comparison of the difference between the average values of the observed variables for multiple groups at the same time, we applied a one-way analysis of variance. In the printout F statistics are presented, which we have examined for homogeneity of variance and with post-hoc tests. The non-parametric Kruskal-Wallis test was used to compare differences depending on the value of the observed variables for multiple groups at the same time. A nonparametric test was chosen when independent variables did not follow a normal distribution.

The relationship between interval variables was measured by non-parametric Spearman correlation coefficient for the distribution of the variables that did not show normal distribution. To determine the power relationship variables, we used the following scale values of the coefficient: 0.01 to 0.19 -insignificant correlations; 0.20 to 0.39 - weak correlations; 0.40 to 0.69 - a moderate correlation; and above 0.70 - strong correlations.

With the program "Pajek" which is dedicated to the analysis and visualization of networks, we examined the centrality of the network. We calculated the input level ("Input degree"), through which we calculate rates of vector points, which takes into account only the input stage. Weighted rates of the network ("Weighted degree") are derived points were the values of lines are taken into consideration. We also determined network centre points, which depend on a stronger degree than the adjacent points (11).

\section{RESULTS}

In the analysis, we first focused on the segmentation of the observed pattern in some heterogeneous groups to study the relationship between psychosocial risk factors and the incidence of low back pain, and their impact on absenteeism. With the help of multivariate methods of hierarchical grouping, based on three variables, we have: 
- I feel low back pain: never (1) - very often (7);

- Low back pain is: mild (1) - very strong (7);

- Low back pain: I do not have problems (1) - very difficult to put up with (7).

We gained 3 balanced groups of professional drivers. In the first group $(n=86)$ drivers without or with slight difficulties are categorized; followed by the second group of drivers $(n=108)$, which include those where the pain is present; and the third group of drivers $(n=81)$, who suffer moderate to severe low back pain and thus related problems. Drivers are therefore categorized into three groups according to the degree of problems with low back pain. We distinguish low, medium and high levels of problems with low back pain.

Absenteeism, which is attributed to low back pain, was defined as absenteeism due to low back pain in relation to the overall absenteeism in the last year using the following questions:

"How long have you been absent from work due to back pain in the last year?" (days); and

"How long have you been absent from work?" (days).

In this way, we have obtained a new variable. The distribution of the new variable is highly asymmetric to the right. 132 respondents were not on sick leave in the last year. If we observe only professional drivers who have been on sick leave in the last year $(n=118)$, on average, half of the subjects $(47.0 \%)$ stated as the reason for absenteeism low back pain.

Table 1 is split in two parts and it shows that there are significant differences due to the original three variables between the groups with varying degrees of problems with low back pain. There is a statistically significant difference in the proportion of absenteeism, which can be attributed to low back pain. Professional drivers who have low levels of problems with back pain were rarely on sick leave due to such reasons (3.4\%), while drivers with an average degree of problems were on sick leave $(16.1 \%)$ due to low back pain. In the third group drivers classified with a high degree of problems with low back pain were on sick leave in half of the cases $(47.3 \%)$ because of low back pain.

It appears that there are significant differences due to all psychosocial risk factors among the groups with varying degrees of problems with low back pain (Table 2). In general, the bigger the problem of low back pain, the bigger the effect of specific psychosocial risk factors on the incidence of pain. Factors that have an overall average value of 4 or more are lifting heavy loads, inadequate working conditions, poor physical condition, regular nights out, and shift work. For better comparison, averages and standard deviations are presented.

The strongest factors associated with absenteeism are dissatisfaction with work $(\mathrm{r}=0.47, \mathrm{p}<0.05)$, inadequate working conditions $(\mathrm{r}=0.47, \mathrm{p}<0.05)$, job loss $(\mathrm{r}=0.44, \mathrm{p}<0.05)$, shift work $(\mathrm{r}=0.44$, $\mathrm{p}<0.05)$, disrespect of management $(\mathrm{r}=0.43, \mathrm{p}<0.05)$, stress $(\mathrm{r}=0.42, \mathrm{p}<0.05)$, lifting heavy loads $(\mathrm{r}=0.40, \mathrm{p}<0.05)$, and less other factors. The above factors are moderately associated with absenteeism. All links are statistically significant.

If we compare the relevant factors that are associated with low back pain and absenteeism, we find that there is indeed a key factor that in most cases is associated with pain, even though it is not the same factor why the drivers were on sick leave in the last year. Factors that vary and are the real reasons behind low back pain are more of psychological nature (dissatisfaction with work, the threat of job loss, irreverent attitude of the management, stress).

Correlation analysis was supplemented with network analysis to find out what psychosocial factors for low back pain are more interconnected and most central. The Spearman correlation coefficient was calculated for correlations between all psychosocial factors, and then considered only for the correlations greater than 0.4 , meaning they were at least moderately based on power. Pairs of variables and their power relationship were entered into the program "Pajek" and checked for the centrality of the network.

The most central psychosocial risk factor is stress, which is correlated with 11 other risk factors, followed by dissatisfaction at work and personal dissatisfaction, which are associated with 10 other factors. Less important factors are smoking ( 3 links) and drinking coffee ( 2 connections). The strength of the correlation according to Spearman correlation coefficient is indicated in Fig. 1.

If we also consider the strength of the relationship, the most important variable is stress and personal dissatisfaction, the least important is personal hygiene. Analysis of the centres of the network proved that the most important (central) psychosocial factor is stress.

Table 3 shows that we extracted a short list of risk factors that are prevalent in all three groups. Key risk factors coincide with those that have an impact on absenteeism. The average strength of connections between risk factors and the degree of problems

Table 1. Descriptive statistics and $F$ test for the characteristics of professional drivers depending on the degree of back pain and absenteeism

\begin{tabular}{|c|c|c|c|c|c|c|c|c|c|c|}
\hline \multirow{3}{*}{ Incidence of low back pain } & \multicolumn{10}{|c|}{ Degree of problems with low back pain } \\
\hline & \multicolumn{2}{|c|}{ Low $(N=86)$} & \multicolumn{2}{|c|}{ Middle ( $\mathrm{N}=108)$} & \multicolumn{2}{|c|}{$\operatorname{High}(\mathrm{N}=81)$} & \multicolumn{2}{|c|}{ Total $(\mathrm{N}=275)$} & \multicolumn{2}{|c|}{ ANOVA } \\
\hline & Mean & SD & Mean & SD & Mean & SD & Mean & SD & $F$ & $\mathrm{p}$ \\
\hline Low back pain is present (never/often) & 2.0 & 0.7 & 3.3 & 1.0 & 5.5 & 1.5 & 3.6 & 1.7 & 223.9 & $<0.001$ \\
\hline Low back pain is (modest/very strong) & 1.4 & 0.5 & 3.6 & 0.9 & 6.0 & 1.1 & 3.6 & 2.0 & 560.1 & $<0.001$ \\
\hline $\begin{array}{l}\text { Low back pain is tolerated (without any } \\
\text { problems/very difficult/tolerated) }\end{array}$ & 1.3 & 0.5 & 3.1 & 1.2 & 5.6 & 1.3 & 3.3 & 2.0 & 334.1 & $<0.001$ \\
\hline \multirow{2}{*}{ Absenteeism } & & & & & & & & & \multicolumn{2}{|c|}{ Kruskal-Wallis test } \\
\hline & & & & & & & & & $x^{2}$ & $\mathrm{p}$ \\
\hline $\begin{array}{l}\text { Average proportion of absenteeism due } \\
\text { to back pain }(\%)\end{array}$ & 3.4 & 0.2 & 16.1 & 0.3 & 47.3 & 0.3 & 22.2 & 0.3 & 105.48 & $<0.001$ \\
\hline
\end{tabular}

SD - standard deviation 
Table 2. Descriptive statistics and F test for risk factors for each group of professional drivers depending on the degree of low back pain

\begin{tabular}{|c|c|c|c|c|c|c|c|c|c|c|}
\hline \multirow{3}{*}{ Risk factors } & \multicolumn{10}{|c|}{ Degree of problems with low back pain } \\
\hline & \multicolumn{2}{|c|}{ Low $(\mathrm{N}=86)$} & \multicolumn{2}{|c|}{ Middle ( $\mathrm{N}=108)$} & \multicolumn{2}{|c|}{ High ( $N=81)$} & \multicolumn{2}{|c|}{ Total $(\mathrm{N}=275)$} & \multicolumn{2}{|c|}{ Kruskal-Wallis test } \\
\hline & Mean & SD & Mean & SD & Mean & SD & Mean & SD & $X^{2}$ & $\mathrm{p}$ \\
\hline Lifting heavy loads & 3.5 & 2.1 & 5.4 & 1.7 & 6.4 & 1.1 & 5.1 & 2.0 & 77.5 & $<0.001$ \\
\hline Unsuitable working conditions & 3.2 & 2.1 & 5.3 & 1.8 & 6.6 & 0.9 & 5.0 & 2.2 & 98.7 & $<0.001$ \\
\hline Poor physical condition & 3.9 & 2.2 & 5.2 & 1.7 & 5.6 & 1.6 & 4.9 & 2.0 & 29.3 & $<0.001$ \\
\hline Regular nights out & 3.1 & 2.0 & 4.4 & 2.1 & 4.6 & 1.9 & 4.1 & 2.1 & 30.2 & $<0.001$ \\
\hline Working in shifts & 2.4 & 1.7 & 4.2 & 2.0 & 5.4 & 1.7 & 4.0 & 2.1 & 83.8 & $<0.001$ \\
\hline Stress & 2.0 & 1.6 & 3.5 & 2.0 & 4.4 & 2.1 & 3.3 & 2.2 & 62.9 & $<0.001$ \\
\hline Death of a family member & 1.9 & 1.9 & 3.2 & 2.4 & 4.4 & 2.4 & 3.1 & 2.4 & 46.4 & $<0.001$ \\
\hline Job loss & 1.8 & 1.8 & 3.1 & 2.1 & 4.3 & 2.2 & 3.1 & 2.3 & 59.5 & $<0.001$ \\
\hline Personal dissatisfaction & 1.9 & 1.6 & 3.1 & 2.0 & 4.0 & 2.1 & 3.0 & 2.1 & 53.2 & $<0.001$ \\
\hline Separation of spouses & 1.6 & 1.6 & 2.8 & 2.3 & 3.9 & 2.4 & 2.7 & 2.3 & 49.3 & $<0.001$ \\
\hline Dissatisfaction with work & 1.4 & 1.1 & 2.6 & 1.7 & 4.0 & 2.1 & 2.7 & 1.9 & 83.9 & $<0.001$ \\
\hline Disrespectful attitude of the management & 1.5 & 1.2 & 2.7 & 2.1 & 3.5 & 2.1 & 2.6 & 2.0 & 53.1 & $<0.001$ \\
\hline Misunderstanding between partners & 1.6 & 1.5 & 2.4 & 2.0 & 3.3 & 2.1 & 2.4 & 2.0 & 41.3 & $<0.001$ \\
\hline Poor relations between colleagues & 1.3 & 0.9 & 2.0 & 1.5 & 2.9 & 2.0 & 2.1 & 1.6 & 43.0 & $<0.001$ \\
\hline Personal hygiene & 1.9 & 1.9 & 1.9 & 1.5 & 2.4 & 1.9 & 2.0 & 1.8 & 7.7 & 0.022 \\
\hline Excessive smoking & 1.7 & 1.6 & 1.8 & 1.7 & 2.1 & 1.6 & 1.9 & 1.7 & 8.7 & 0.013 \\
\hline Excessive coffee drinking & 1.5 & 1.2 & 1.7 & 1.5 & 2.1 & 1.7 & 1.8 & 1.4 & 14.1 & $<0.001$ \\
\hline
\end{tabular}

SD - standard deviation

with low back pain (low, medium, high) was calculated using Spearman correlation coefficient. Only correlations greater than 0.4 were considered for the calculation.

\section{DISCUSSION}

Through analysis, we found that respondents quite often experience low back pain; on average it is assessed as moderately strong. Our findings are consistent with other researchers that conducted research on pain in the lower part of the spine among professional drivers. It is a fact that drivers belong to the group of occupations with the greatest risk of pain (12), because low back pain is more common among those workers who practice their profession in sitting positions, unlike those who work and have changeable rotating body positions $(12,13)$. Professional drivers are at greater risk for developing low back pain because they are exposed to whole-body vibration, forced positions and handling of goods $(14,15)$. Alperovitch et al. (16) found that $45.4 \%$ of bus drivers experience low back pain within 12 months. They

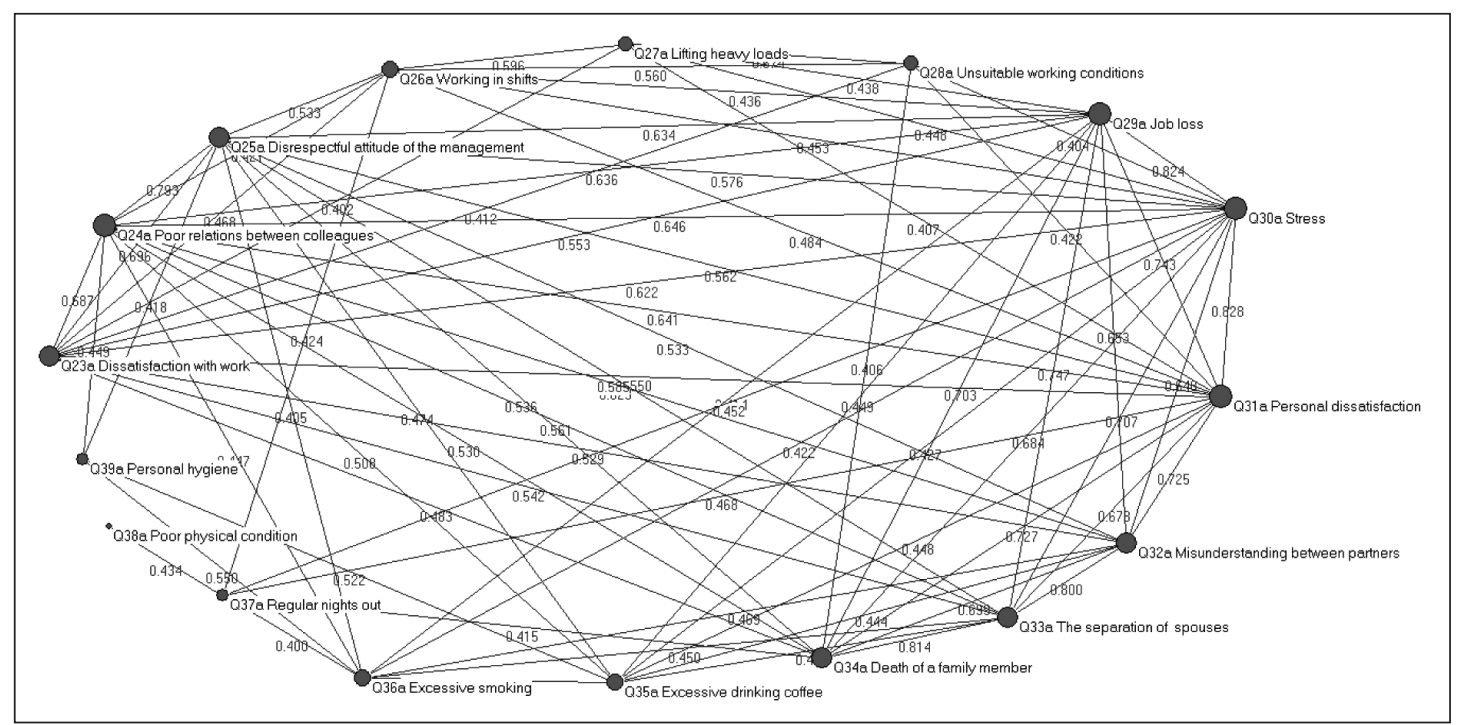

Fig. 1. Network centres. 
Table 3. Analysis of the centrality and relationship between psychosocial factors for low back pain

\begin{tabular}{|c|c|c|c|c|c|c|}
\hline \multirow{3}{*}{ Risk factors } & \multicolumn{6}{|c|}{ Degree of problems with low back pain } \\
\hline & \multicolumn{2}{|c|}{ Low } & \multicolumn{2}{|c|}{ Middle } & \multicolumn{2}{|c|}{ High } \\
\hline & $\begin{array}{c}\text { Number } \\
\text { of connections }\end{array}$ & $\begin{array}{l}\text { Average strength } \\
\text { of connections }\end{array}$ & $\begin{array}{c}\text { Number } \\
\text { of connections }\end{array}$ & $\begin{array}{l}\text { Average strength } \\
\text { of connections }\end{array}$ & $\begin{array}{c}\text { Number } \\
\text { of connections }\end{array}$ & $\begin{array}{l}\text { Average strength } \\
\text { of connections }\end{array}$ \\
\hline Stress & 8 & 0.52 & 6 & 0.50 & 4 & 0.34 \\
\hline Personal dissatisfaction & 7 & 0.50 & 5 & 0.47 & 3 & 0.32 \\
\hline Job loss & 7 & 0.49 & 8 & 0.50 & 5 & 0.40 \\
\hline $\begin{array}{l}\text { Poor relations between } \\
\text { colleagues }\end{array}$ & 6 & 0.40 & 10 & 0.43 & 6 & 0.33 \\
\hline $\begin{array}{l}\text { Disrespectful attitude } \\
\text { of the management }\end{array}$ & 5 & 0.33 & 10 & 0.42 & 5 & 0.27 \\
\hline Dissatisfaction with work & 5 & 0.38 & 5 & 0.34 & 5 & 0.28 \\
\hline
\end{tabular}

Statistical significance for all $<0.01$

related the cause of low back pain to ergonomic factors, principally to uncomfortable seats and uncomfortable back support. As psychosocial factors significantly correlated with lower back pain workers noted limited free time periods over a day's work and the heavy traffic on bus routes. Likewise, Gangopadhyay and Dev (17) found that low back pain is the factor limiting the social and professional lives of bus drivers. The survey results demonstrate that bus drivers are under a lot of stress caused by unsafe working conditions, which indirectly affects the health and labour productivity. Bovenzi (18) noted that the physical workload of professional drivers is a significant predictor of low back pain. Tamrin et al. (19) wanted to determine the risk factors associated with the reporting of low back pain in their study, which involved 760 drivers of commercial vehicles. They assessed the prevalence of low back pain among drivers in view of the forced posture of the drivers' torso (bending forward, leaning, sitting up straight and twisting). In addition, they evaluated continued driver environmental conditions. They found the prevalence of low back pain in $60.4 \%$ of drivers and also found that different combinations of risk increase low back pain rates among Malaysian bus drivers.

Robb and Mansfield (20) noted that professional driving contributes to the high rate of occurrence of low back pain. Varied risk factors include prolonged sitting, bad body position, exposure to whole-body vibration and other parallel factors such as heavy lifting, poor diet and a number of psychosocial factors. Out of 192 drivers surveyed, the majority $(81 \%)$ reported musculoskeletal pain in the last 12 months and $60 \%$ of drivers complained of low back pain. Szeto and Lam (21) noted that work-related musculoskeletal disorders affect a variety of workers including the drivers of larger vehicles. With this study, the authors wanted to draw attention to the prevalence and nature of work-related musculoskeletal disorders in drivers of double-decker buses. $60 \%$ of respondents reported pain in the neck, back, shoulders, knees, and thighs.

In this study, we tried to determine the association between risk factors of pain in the lower part of the spine and back pain among professional drivers. We discovered that the incidence of low back pain is significantly influenced by the following risk factors: lifting heavy loads, inadequate working conditions, poor physical condition, regular nights out, and shift work. Using the program "Pajek" we have found that stress is the most important risk factor, which is associated with 11 other risk factors.

Our findings are consistent with the findings of Bigos et al. (22), who stated that the risk factors for lumbar spine injuries were more common in workers who are dissatisfied with their work and rarely enjoy their work. Sanders (23) also mentioned dissatisfaction with the work, heavy physical strain, stress or abuse as risk factors for low back pain. Bongers et al. (24) found in their study that in the forefront of back problems are in particular poor work control, monotonous work, physically demanding work, time constraints, and a lack of social support.

Pain in the lower part of the spine among professional drivers represents a huge financial cost for labour organizations, society and individuals as well as for health funds. Common absenteeism, compensation for absence from work (sick leave) and costs which may occur due to errors in the work (compensation to individuals and organizations, stress, taking painkillers, sudden attacks of pain in the low back, which can cause an accident, and all the consequences) add a further burden (25). Low back pain and a high cost associated with treatment, absenteeism and disability represent a major health problem in developed countries (26). In this study, we wanted to determine whether the occurrence of low back pain is associated with absenteeism among professional drivers. We have found that most strongly associated factors with absenteeism are dissatisfaction with work, inadequate working conditions, job loss and shift work, inappropriate attitude of management, stress, and lifting heavy loads. Also, the study carried out by Coste et al. (27) found that sick leave is strongly dependent on socioeconomic factors and patient's satisfaction with work. Grossi et al. (28), who studied the connection between psychosocial variables and absenteeism due to muscular skeletal pain, found that the strongest predictors for muscular skeletal pain are especially symptoms of burnout and responses to post-traumatic stress. They found that absenteeism is associated with the ways of dealing with problems, disability and emotional stress.

\section{CONCLUSION}

The problem of low back pain is certainly a topical issue. This research may help to a better understanding of psychosocial risk 
factors for low back pain that have the most significant impact on the incidence and absenteeism among professional drivers. Our analysis of the first hypothesis indicates that the presence of psychosocial factors in the life of a driver significantly increases the presence of low back pain. Through network analysis, we demonstrated that the central psychosocial risk factor represents the stress itself.

For the second hypothesis, we found that among drivers with more intense and frequent pains in the low back sick leave is more frequent. We can conclude that the incidence of low back pain among professional drivers has a statistically significant impact on absenteeism. The results of our study are to some extent consistent with the findings of other authors within this field of study. Most of these authors assessed the impact of risk factors on the incidence of low back pain.

Researchers have emphasized ergonomic factors, factors of workplace risk and person risks. Our study has shown that psychosocial factors are also very important (29). The most important cause of the incidence of low back pain is stress, followed by personal dissatisfaction in connection with personal problems and difficulties in relationships at work and at home as well as dissatisfaction at work. It should be noted that stress plays a central role, and as such it represents a key risk factor for the incidence of low back pain. Stress is fixed between all other risk factors that we have identified. Therefore, the main efforts should focus on coping with stress and its management (30). This would contribute to improving wellbeing and increasing efficiency at work and consequently lower absenteeism. For this reason we are increasingly oriented towards a biopsychosocial model of treatment and towards the multidisciplinary approach in the treatment of low back pain.

In our study, we limited our research to risk factors, such as heredity, gender, age, body build, physical preparedness, habits and customs, social class, physical risk factors, and factors related to work and working environment, such as physical factors and psychosocial factors associated with work. For further research, other psychosocial factors should be included. It also seems important to us that further researches focus primarily on prevention. To highlight the problem of low back pain, it is important to actively promote the biopsychosocial treatment of low back pain and multidisciplinary approach.

\section{Conflict of Interests}

None declared

\section{REFERENCES}

1. Frank A. Low back pain. BMJ. 1993 Apr 3;306(6882):901-9.

2. Jin K, Sorock GS, Courtney T, Liang Y, Yao Z, Matz S, et al. Risk factors for work-related low back pain in the People's Republic of China. Int J Occup Environ Health. 2000 Jan-Mar;6(1):26-33.

3. Krause N, Ragland DR, Fisher JM, Syme SL. Psychosocial job factors, physical workload, and incidence of work-related spinal injury: a 5-year prospective study of urban transit operators. Spine (Phila Pa 1976). 1998 Dec 1;23(23):2507-16.

4. Krčevski Škvarč N, editor. Proceedings of Interdisciplinary Consultation on Low Back Pain; 1999 May 7-8; Maribor. Maribor: Slovenian Association for Pain Management; 1999. (In Slovenian.)

5. Krčevski-Škvarč N. Towards proceedings. In: Krčevski-Škvarč N, Salihovič M, editors. Proceedings of the Meeting of Experts on Low Back Pain; 2000 Nov 24-25; Moravske Toplice. Maribor: Slovenian Association for Pain Management; 2000. p. 11. (In Slovenian.)
6. Waddel G. The back pain revolution. Edinburgh: Churchill Livingstone; 1998.

7. Kresal F. Biopsychosocial model of back pain treatment. In: Rihtar A, Fuchs T, editors. Improving the quality of physiotherapy: Proceedings of the 6th Symposium of Physiotherapists of Slovenia and Chamber of Physiotherapists of Slovenia; 2000 May 11-13; Šentjur. Ljubljana: ZFS; 2000. p. 59-63. (In Slovenian.)

8. Croft PR, Papageorgiou AC, Ferry S, Thomas E, Jayson MI, Silman AJ. Psychologic distress and low back pain. Evidence from a prospective study in the general population. Spine (Phila Pa 1976). $1995 \mathrm{Dec}$ $15 ; 20(24): 2731-7$

9. Mannion AF, Dolan P, Adams MA. Psychological questionnaires: Do "abnormal" scores precede or follow first time low back pain? Spine. 1997;21(22):2603-11.

10. Lewis CA, Johnson PW. Whole-body vibration exposure in metropolitan bus drivers. Occup Med (Lond). 2012 Oct;62(7):519-24.

11. Mrvar A, Batagelj V. Pajek: programs for analysis and visualization of very large networks: reference manual. Ljubljana; 1996.

12. Latham J, Davis BD. The socioeconomic impact of chronic pain. Disabil Rehabil. 1994 Jan-Mar;16(1):39-44.

13. Magora A. Investigation of the relation between low back pain and occupation. V. Psychological aspects. Scand J Rehabil Med. 1973;5(4):191-6.

14. Siško PK, Videmšek M, Karpljuk D. The effect of a corporate chair massage program on musculoskeletal discomfort and joint range of motion in office workers. J Altern Complement Med. 2011 Jul;17(7):617-22.

15. Okunribido OO, Shimbles SJ, Magnusson M, Pope M. City bus driving and low back pain: a study of the exposures to posture demands, manual materials handling and whole-body vibration. Appl Ergon. 2007 Jan;38(1):29-38.

16. Alperovitch-Najenson D, Santo Y, Masharawi Y, Katz-Leurer M, Ushvaev D, Kalichman L. Low back pain among professional bus drivers: ergonomic and occupational-psychosocial risk factors. Isr Med Assoc J. 2010 Jan;12(1):26-31.

17. Gangopadhyay S, Dev S. Effect of low back pain on social and professional life of drivers of Kolkata. Work. 2012;41 Suppl 1:2426-33.

18. Bovenzi M. A longitudinal study of low back pain and daily vibration exposure in professional drivers. Ind Health. 2010;48(5):584-95.

19. Tamrin SBM, Yokoyama K, Aziz N, Maeda S. Association of risk factors with musculoskeletal disorders among male commercial bus drivers in Malaysia. Hum Factors Ergon Manuf Service Indust. 2014;24(4):369-85.

20. Robb MJ, Mansfield NJ. Self-reported musculoskeletal problems amongst professional truck drivers. Ergonomics. 2007 Jun;50(6):814-27.

21. Szeto GP, Lam P. Work-related musculoskeletal disorders in urban bus drivers of Hong Kong. J Occup Rehabil. 2007 Jun;17(2):181-98.

22. Bigos SJ, Battié MC, Spengler DM, Fisher LD, Fordyce WE, Hansson $\mathrm{TH}$, et al. A prospective study of work perceptions and psychosocial factors affecting the report of back injury. Spine (Phila Pa 1976). 1991 Jan;16(1):1-6.

23. Sanders SH. Risk factors for chronic, disabling low back pain: an update for 2000. APS Bull. 2000;10(2):4-5.

24. Bongers PM, de Winter CR, Kompier MA, Hildebrandt VH. Psychosocial factors at work and musculoskeletal disease. Scand J Work Environ Health. 1993 Oct;19(5):297-312.

25. Bovenzi M. A prospective cohort study of neck and shoulder pain in professional drivers. Ergonomics. 2015;58(7):1103-16.

26. Shraim M, Cifuentes M, Willetts JL, Marucci-Wellman HR, Pransky G. Length of disability and medical costs in low back pain: Do state workers' compensation policies make a difference? J Occup Environ Med. 2015 Dec;57(12):1275-83.

27. Coste J, Delecoeuillerie G, Cohen de Lara A, Le Parc JM, Paolaggi JB. Clinical course and prognostic factors in acute low back pain: an inception cohort study in primary care practice. BMJ. 1994 Feb 26;308(6928):57780 .

28. Grossi G, Soares JJ, Angeslevä J, Perski A. Psychosocial correlates of long-term sick-leave among patients with musculoskeletal pain. Pain. 1999 Apr;80(3):607-19.

29. Roblek V, Bertoncelj A. Impact of corporate social responsibility on the OTC drugs consumers. Amfiteatru Economic. 2014;16(35):12-25.

30. Tziner A, Birati A. Assessing the financial value of human resource management programs and employee behaviors: a critical tool still coming of age. Amfiteatru Economic. 2015;17(9):1259-72.

Received April 9, 2015

Accepted in revised form September 12, 2016 